Article

\title{
Exploring Residents' Perceptions and Attitudes towards Sustainable Tourism Development in Traditional Villages: The Lens of Stakeholder Theory
}

\author{
Hongmei Song ${ }^{1}$, Chris $\mathrm{Zhu}^{2, *}$ and Lawrence Hoc Nang Fong ${ }^{3}$ \\ 1 Faculty of International Tourism and Management, City University of Macau, Macau SAR 999078, China; \\ T19092100135@cityu.mo \\ 2 School of Tourism Management, Macau Institute for Tourism Studies, Macau SAR 999078, China \\ 3 Faculty of Business Administration, University of Macau, Macau SAR 999078, China; \\ lawrencefong@um.edu.mo \\ * Correspondence: H210052@ift.edu.mo
}

check for

updates

Citation: Song, H.; Zhu, C.; Fong, L.H.N. Exploring Residents'

Perceptions and Attitudes towards

Sustainable Tourism Development in

Traditional Villages: The Lens of

Stakeholder Theory. Sustainability

2021, 13, 13032. https://doi.org/

$10.3390 /$ su132313032

Academic Editors: Colin Michael Hall and Marc A. Rosen

Received: 10 October 2021

Accepted: 20 November 2021

Published: 25 November 2021

Publisher's Note: MDPI stays neutral with regard to jurisdictional claims in published maps and institutional affiliations.

Copyright: (c) 2021 by the authors. Licensee MDPI, Basel, Switzerland. This article is an open access article distributed under the terms and conditions of the Creative Commons Attribution (CC BY) license (https:// creativecommons.org/licenses/by/ $4.0 /)$.

\begin{abstract}
As Chinese traditional villages are receiving increasing attention from the country, society and business in terms of sustainable tourism development, their residents' perceptions have not been thoroughly investigated. To contribute to the literature, this qualitative study, which was based on stakeholder theory, conducted semi-structured in-depth interviews with 12 different stakeholders in Hongcun, one of the most well-known traditional villages in China. Using grounded theory approach, this study found that residents' perceptions and attitudes of sustainable development differed in four main areas-economic, environmental, social, and cultural—and several sub-themes were developed to influence these four areas. The study results have important theoretical and practical implications for current sustainable tourism development in traditional villages. In particular, these results have substantial value for the country, society, and business levels with respect to developing traditional village sustainable tourism based on the perceptions and attitudes of the residents.
\end{abstract}

Keywords: resident perception; resident attitude; sustainable development; stakeholder theory; in-depth interview

\section{Introduction}

In China, traditional villages are the "living fossils" of village dwellings in agrarian civilization, carrying traditional Chinese settlement culture, traditional folk culture, and traditional village architecture [1]. A previous study found that the number of traditional villages has declined dramatically since the 1980s, and some of them have been more severely damaged [2]. The official website of the Ministry of Housing and Urban-Rural Development of the People's Republic of China shows that as of 2019, a total of 2666 villages nationwide are listed in the "List of Traditional Villages of China". Considering the gradual decline and damage of traditional villages, the country, society, and businesses need to think about how to slow down this trend and to sustain the traditional villages through tourism development. However, when reviewing the literature, few studies have been conducted to examine the relevant aspects of Chinese traditional villages, such as how to develop them under COVID-19? Therefore, the study fills this research gap from a sustainable development perspective.

Sustainable development as an essential tourism development concept has led to conserving and using traditional village cultural heritage through sustainable tourism development policies [3]. However, how can these villages effectively develop sustainable tourism resources considering differences in residents' perceptions and attitudes? Furthermore, how can the relationship between residents, tourists, government, and tourism developers be coordinated without destroying the original ecology of the ancient villages 
and causing community conflicts? Meanwhile, ensuring the economic stability of traditional villages is gradually becoming a research hotspot and problematic point in the study of sustainable tourism in traditional villages. Therefore, this paper argues that it is necessary to focus on the differences in residents' perceptions as well as attitudes on the sustainable development of traditional villages.

Previous academic studies on the sustainable development of traditional villages have focused on traditional village tourism business models, analysis of traditional village tourism resources, community conflicts, and community interests in tourism sites $[4,5]$. Studies involving residents' perceptions mainly focus on factors affecting the perceptions and attitudes of residents in tourist places, related theories, and analytical methods [6]. Given the observation of the literature, the main problems of the current relevant studies are as follows: (1) most studies on the impact of sustainable development of traditional villages have been conducted from a single perspective of residents' perceptions or attitudinal differences, and there is a lack of discussion on both as antecedents; (2) residents' perceptions of tourism impacts are their subjective perceptions of tourism impacts, and quantitative studies have limitations. In this regard, a qualitative interview method is appropriate.

Stakeholders play a critical role as the most essential vehicle for residents' perceptions and attitudes $[7,8]$. Therefore, it is necessary to explore residents' perceptions as well as attitudes from the stakeholder's perspective. Stakeholder theory has been well applied in tourism research $[9,10]$. Previous studies have argued that the need for the involvement of different stakeholders in tourism planning is becoming increasingly important [11,12]. At the same time, ensuring effective destination planning is a complex process. This is because a wide variety of stakeholders need to be considered in the process. They have different opinions, multiple issue scenarios, and different interests [7,13]. The study by [9] shows that community planners and destination management organizations must pay attention to all community stakeholders. Based on the concept of achievable development and stakeholder theory, these organizations must communicate with local communities and tourists. The study by [13] found that based on stakeholder theory, how corporate social responsibility (CSR) interacts with corporate strategy and corporate financial performance (CFP), and how tourism practitioners can identify which CSR activities may affect CFP management insights, are valuable theoretical insights. Therefore, the lessons from these studies are necessary as well as relevant for the current research to consider the perceptions as well as attitudinal differences of traditional village residents based on different stakeholder perspectives. However, as the aforementioned studies have highlighted the importance of applying stakeholder theory in different tourism experience, research on traditional villages based on stakeholder theory is limited. Therefore, it is necessary for the current study to explore the perceptions and attitudes of traditional village residents based on stakeholder theory to fill the gap of previous studies.

According to the aforementioned research gap, this research addresses two research questions: (1) What are stakeholders' perceptions and attitudes towards sustainable tourism of traditional villages? (2) What factors affect resident perception and attitude towards the sustainable tourism development of traditional villages?

In summary, this study explores the interpretation of residents' perceptions and attitudes toward sustainable tourism development. In addition, further understanding of the factors that influence the perceptions and attitudes of different stakeholders towards sustainable development of traditional villages is presented. Moreover, a theoretical framework based on resident perception and attitude will also be developed. The contributions of this study may be seen as threefold. First, this pioneering study enriches stakeholder theory regarding traditional villages tourism. Second, the paper lays the theoretical ground to develop scales for measuring resident perception and attitude in traditional villages. Third, the paper provides insight into the impact of sustainable tourism perceived by residents, which not only helps to improve the tourist experience but also optimizes the positive effects of economic and socio-cultural development; it also helps to reduce the 
conflicts and contradictions between tourists and residents, as well as the environmental damage caused by tourism development.

In the following chapters, Section 2 will critically review prior studies in the relevant area. Section 3 will explain how we use the qualitative research method to collect data and perform data analysis. Section 4 will discuss the theoretical and practical implications of the qualitative findings. Section 5 will conclude the findings and articulate the study's limitations.

\section{Literature Review}

\subsection{Stakeholder Theory}

Stakeholder theory was first proposed by [14] and was defined as "any group or individual who can influence an organization to achieve its goals or who is influenced by that goal" (p. 46). Stakeholder theory argues that a successful strategy considers the interests of all stakeholders' claims [15]. At the same time, as stakeholders, individuals or groups need to have certain rights and legitimacy to participate and must have the position, ability, and appropriate means to influence corporate decisions. Stakeholder theory has been introduced in sustainable tourism research based on this concept $[10,16]$. For example, Gursoy et al. [16] argue that sustainable tourism development requires the orderly participation of all stakeholders and that the attitudes and interests of different stakeholders towards tourism development should be considered in an integrated manner and their active response and participation should be encouraged. Easterling [17] explores the role of residents in tourism and finds that active participation of residents is the key to successful tourism development. If residents' expectations are not met, they will have a negative attitude towards tourism development. In addition to this, stakeholder theory has been applied to explore the heterogeneity of residents' positive and negative perceptions or attitudes and stakeholders' influence, participation, and rights towards sustainable tourism development $[18,19]$. Despite many studies that have integrated stakeholder theory in their research of different destinations, little is known about the link between stakeholder theory and sustainable tourism development in traditional villages.

Sustainable tourism development has brought about an evolving stakeholder group. Usually, community residents, tourists, local governments, and tourism businesses are considered the most common stakeholder groups in tourism development models [20], where community residents are considered the core stakeholders of tourism destinations [8]. Previous studies have concluded that the absence of residents' support for community tourism development will lead to a negative impact such as a decrease in the core attractiveness of the destination and will result in a lower quality of tourism experience [20]. In addition, Almeida-García et al. [21] found that differences in socio-demographic variables, such as educational background, place of birth, and the length of time respondents lived in the community, had a significant impact on perceived tourism impacts. However, the conditions of community participation and support for tourism development depend on how local residents perceive the impact of tourism development on their communities [22]. From this perspective, the study argues the need to explore the evolution of stakeholder interests in traditional villages to support destination residents for sustainable tourism development. In view of this, it is meaningful to identify the perceptions and attitudes of residents towards sustainable tourism based on the stakeholder theory in traditional village tourism.

\subsection{Sustainable Tourism Development}

Sustainable tourism development has gradually become an essential factor for destinations to gain a long-term competitive advantage [23]. Tourism development is a multidimensional structure that includes economic, social, environmental, and cultural aspects [24]. Previous study argues that any country or place (including villages) should balance economic, environmental, and social elements [25]. This aligns with the view of Bulter [26] that sustainable development can be broadly divided into economic, environ- 
mental and social components. In addition, culture is a key factor that cannot be ignored when thinking about the conservation and use of traditional villages. The cultural and social component aims to ensure the diversity, difference, autonomy, and inclusiveness of individuals and the cultures they load in cultural transmission [27]. According to some scholars, achievability includes three dimensions: economic, environmental, and sociocultural, characterized by ecological sensitivity, economic viability, and social equity, with synergistic development as its ultimate development goal [18].

As a "living" natural and cultural heritage, traditional villages have higher requirements for sustainable development. Tourism development in traditional villages may positively and negatively impact the inhabitants, with various effects on the destination's economy, socio-culture, and environment [24]. Furthermore, tourism development may induce adverse effects such as deterioration of the traditional local culture of the host country [28] and increased traffic congestion [29]. Therefore, only by coordinating tourism development with economic, environmental, and social-cultural resources can we seek a "win-win" path for ancient village heritage conservation and tourism development to ensure the sustainable development of ancient village tourism. However, research related to sustainable tourism in traditional villages is limited. Therefore, in view of this gap, this study rethinks economically, socio-culturally, and environmentally sustainable tourism in traditional villages based on the perspectives of different stakeholders.

\subsection{Residents' Perception and Attitude in Tourism}

Since the 1970s, resident perception has become a popular topic of research among foreign scholars [30]. As a result, different scholars have conducted in-depth and extensive research on residents' tourism perceptions from different disciplinary perspectives and research methods and have achieved fruitful theoretical results [31,32]. Initially, when it comes to residents' perceptions, scholars have mainly focused on residents' perceptions of the economic impacts brought by tourism. However, with the deepening of tourism, they began to explore residents' perceptions of tourism from various aspects such as economic, social, and environmental [33]. As a result, current studies concluded that tourism impacts on communities include four aspects: economic impacts, social impacts, cultural impacts, and environmental impacts, and each aspect contains both positive and negative categories [34]. Moreover, community residents' perceptions of these tourism impacts are often closely related to their attitudes toward tourism development [35].

Research has found that residents support tourism development if they believe it will positively impact them; conversely, they are opposed to tourism development if they believe it will harm them. Studies by Guo et al. [36] and Rasoolimanesh et al. [37] suggest that positive tourism impact perceptions promote development, and negative tourism impact perceptions weaken support for tourism development. Almeida-García et al. [21] found that the economic impact of tourism is positive, the social impact is negative, and the environmental impact is mixed. Thus, multiple factors influence the residents' perceptions and attitudes towards tourism de-development. At the same time, residents believe that tourism can contribute to the development of the local economy and welcome it. However, tourism may bring adverse problems, such as traffic congestion, environmental pollution and damage, and increased crime, and they are opposed to tourism development [38]. Residents' perceptions and attitudes toward tourism are critical to creating an attractive and conducive environment for sustainable tourism. Therefore, based on the importance of residents' perceptions and attitudes, from this perspective, this study argues that a more in-depth study of traditional villages is necessary to reveal the potential mechanisms that influence residents' perceptions and attitudes in this context.

\subsection{Resident Perceptions, Attitudes, and Sustainable Tourism Development}

The sustainable development of tourist places depends not only on the availability of attractions and services but also on the attitudinal support of the inhabitants [16]. Therefore, tourism resource development and tourism development in tourist areas aim to improve 
the lives and well-being of the residents of tourist communities [39]. For example, the inhabitants of tourist communities and their cultural atmosphere, rituals, festivals, and habits embody the history and cultural heritage of the destination and are an attraction in themselves; therefore, encouraging residents to inherit and preserve their original cultural traditions is an essential component of community resource and tourism development. At the same time, as an essential stakeholder in the development of destinations, the development of tourism cannot be separated from the welcoming attitude of residents towards tourists, as happy hosts are more likely to welcome tourists to generate higher revisit rates [40]. From this perspective, exploring resident perceptions and attitudes has essential implications for sustainability.

People want to profit from tourism development in the early stages of sustainable tourism development, and economic gains may be a key factor influencing residents to support tourism [41]. However, as tourism develops, those who do not see themselves as benefiting from tourism may show more negative attitudes towards tourism development [40]. In addition to economic factors, positive attitudes of residents towards tourism are also related to socio-cultural factors. For example, a study by [37] found that solid resident support for tourism is closely related to the role of tourism in strengthening and maintaining socio-cultural norms and values. As the study progressed, scholars found that environmental involvement influenced their level of support for tourism [42]. The tourism perceptions and attitudes of community residents are also diverse and complex [35]. As critical stakeholders in the development of tourism sites, residents' participation and cooperation are critical factors in the sustainability of local tourism [43], and there is a positive correlation between residents' perceptions and attitudes and their support for sustainable tourism development [44]. However, when reviewing the literature, few relevant studies have linked residents' perceptions and attitudes to traditional villages. Therefore, this study considers it relevant to explore the attitudes of different stakeholders towards the sustainable development of traditional villages.

\section{Research Method}

\subsection{Brief Description of the Research Procedure}

The current study explores the perceptions and attitudes of traditional village residents towards sustainable development of traditional villages, mainly through semi-structured in-depth interviews. Since qualitative research does not require sample size, i.e., reaching theoretical saturation is important. Additionally, this can be understood as a limitation of the research method, the generalizability of data generalized through small samples may be limited. Based on this limitation, the generalizability of the current study may only be limited to similar traditional villages in China. Figure 1 presents a brief of the research procedure.

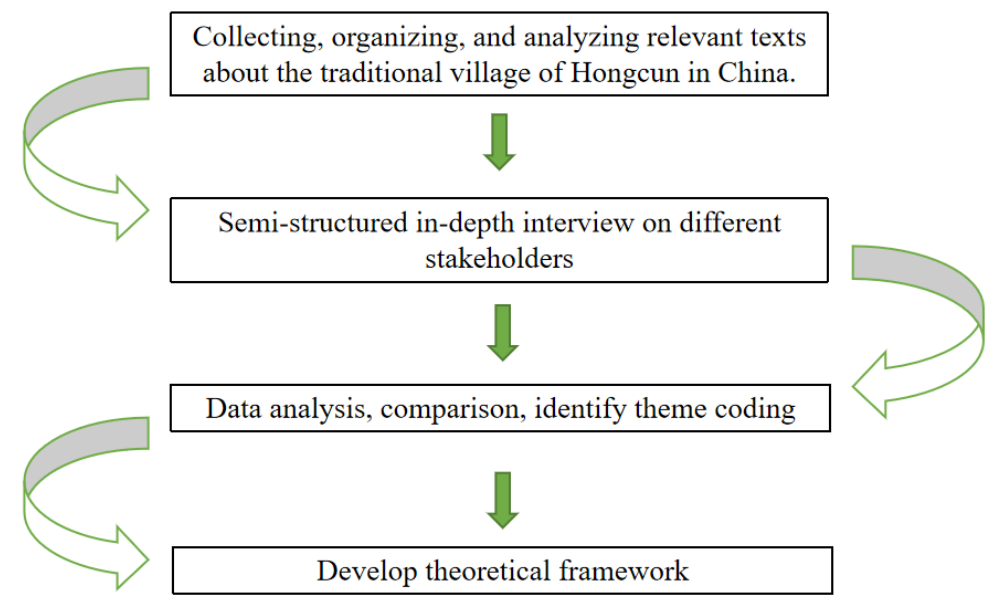

Figure 1. Brief of the research procedure. 


\subsection{Qualitative Approach}

Qualitative research is appropriate for this study, as little is known about resident perception and attitude toward sustainable tourism in traditional villages [45]. To understand the resident perception and attitude of sustainable development, an in-depth interview is a powerful method to understand respondents' perspectives; therefore, 12 different stakeholders were interviewed in this study [46]. The interviewees included different stakeholders, including guides, B\&B owners, hotel owners, university teachers, residents, government staff, village officials, freelance painters, and scholars. To understand the interviewees' perceptions and attitudes toward sustainable tourism, semi-structured interview questions guided their thoughts in the interview [47]. Before the interview, the authors discussed the interview questions to ensure the reliability of the questions. These interview items included: Q1: Are you local residents, or how long have you lived here? The aim is to filter the potential respondents. If they fit the interview standard, the following questions are posed: Q2: What are your views on the sustainable tourism development of local traditional villages? Q3 In what ways has sustainable tourism in local traditional villages impacted your life? During the Chinese-English translation process, two professional scholars proficient in both Chinese and English checked the original text and the translated version to ensure the reliability of the interview content. As the interview construct follows semi-structured interview principles, interviewers continually follow up with interview questions. During the interview, interviewers avoided leading questions or interrupting the interviewees [48].

The interview questions prompted respondents to express their thoughts. The interview time ranges from 50 to $90 \mathrm{~min}$, and each interview was digitally recorded and transcribed verbatim. During the interview, we repeatedly confirm their answers and ensured the reliability and validity of interview data. The literature reveals that there is no strict requirement for sampling in qualitative research [49]. Thus, this study did not set the initial sampling in the current study until all qualitative data had achieved theoretical saturation. Finally, the study concluded with 12 samples. The criteria for theoretical saturation are as follows: (1) almost all respondents answered the same theme code; (2) the interviewers discussed the research results together with the interviewees and there was no further controversy with the results. When the above two criteria were met, we considered theoretical saturation to have been achieved.

\subsection{Study Site}

Located in Yixian County (Anhui Province, China), Hongcun is a traditional village that carries Anhui culture and features precious historical and cultural heritage, approved as "World Cultural Heritage" by UNESCO. Thus, after 30 years of tourism development, Hongcun is considered to be a well-preserved place of world cultural heritage. However, with the increasing number of tourists, the traditional village has been sanded and commercialized, and the production and life of the residents have been greatly affected, which has led to divergence in residents' perceptions. As a result, the conflicts between residents and local government, enterprises, and tourists have become intense. For this reason, this paper selects the most typical and representative ancient residential heritage site, Hongcun, as a case study. Figures 2 and 3 indicated the location and sceneries of Hongcun. 


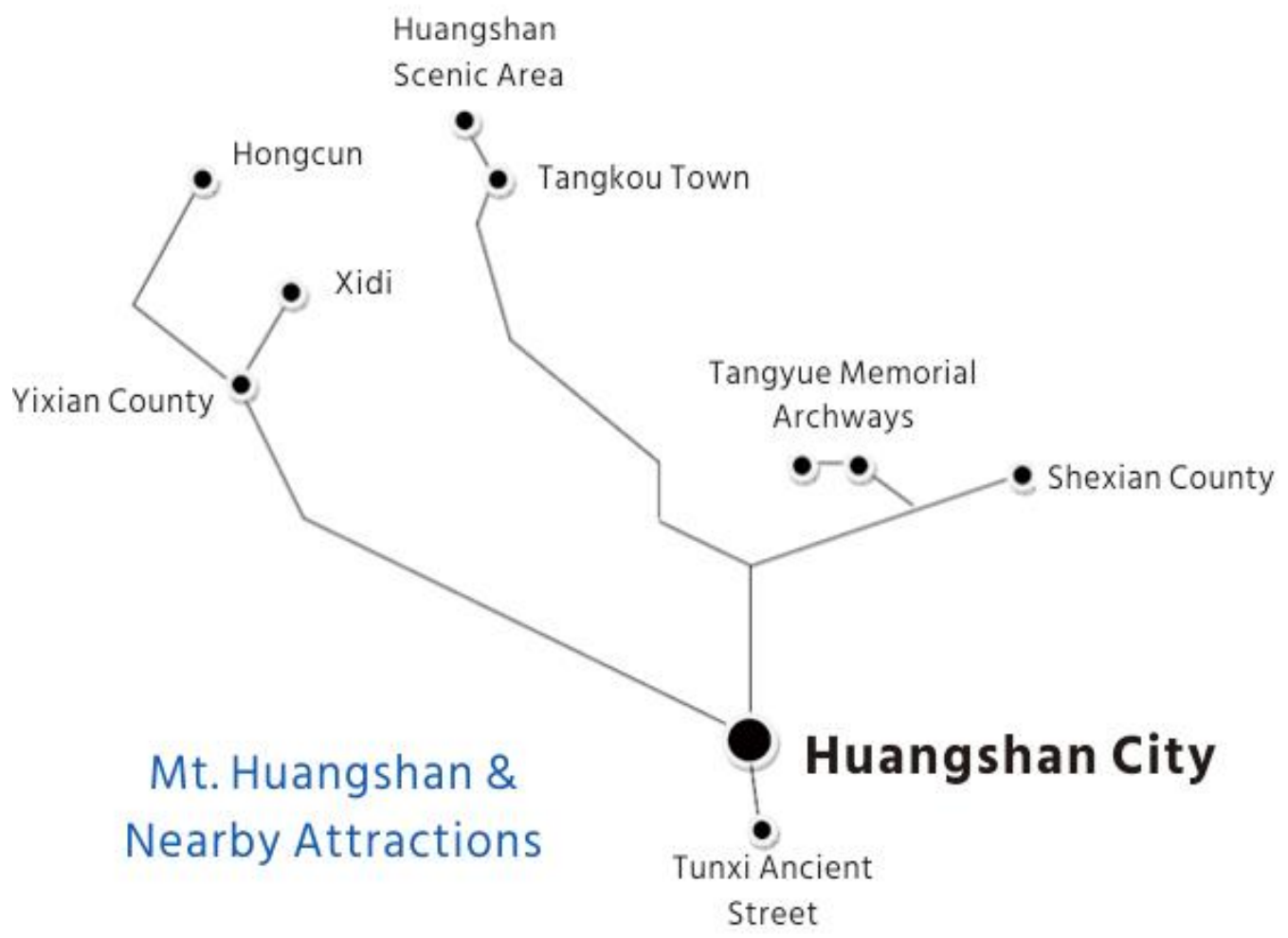

Figure 2. Study location (China City Tours, 2021).
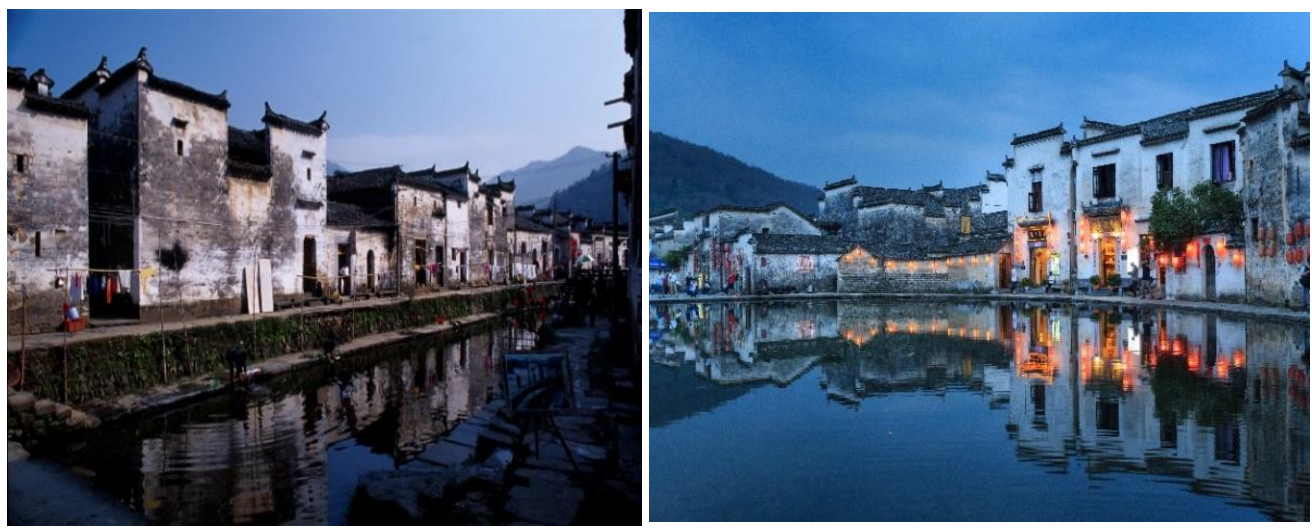

Figure 3. Scenery of Hongcun, China.

\subsection{Data Collection}

To improve the reliability and validity of the qualitative research, this study was divided into two stages. (1) Collecting, organizing, and analyzing relevant texts about the traditional village of Hongcun on China Knowledge Network and tourism online platforms; and (2) the researchers conducted in-depth field interviews in Hongcun from July 2019 to January 2020. In addition, because it was challenging to collect information through face-to-face interviews in the field during the COVID-19 pandemic, centralized interviews were conducted from 12-28 March 2020, using online video, voice, telephone, or written text responses with the support and cooperation of the tourism authorities in Huangshan City. The data collection and analysis of the above two phases were conducted independently, allowing the research results to be complemented and corroborated.

To better explore the perceptions of traditional village community residents and their influencing factors, the interviews in this study were divided into two parts. The first part is the basic profile of the interviewees; the second part is the positive and negative impacts of Hongcun on the local economy, society, culture, and environment. Through analysis 
and comparison, the constitutive dimensions affecting the sustainable development of the destination were identified from the perspective of tourists' perceptions. The group classified all the texts after data collection and numbered the respondents, with the first respondent being numbered $\mathrm{P} 01$, and so on, until the numbering of all respondents was completed. Table A1 in the Appendix A shows the background of the respondents.

\subsection{Data Analysis}

When conducting the data analysis, the study used the grounded theory for coding. Coding based on grounded theory has become a familiar and appropriate method used in many qualitative studies in tourism [50,51]. Before coding the data, the four researchers read and proofread the original data several times and coded the data independently to improve the reliability of the data coding. The data coding process was based on the three coding steps of [52]. They are open, axial, and selective coding processes.

In the first stage of open coding, all researchers coded the data individually, and in this process, we used the qualitative analysis software tool Nvivo 12 plus. The analysis capabilities of this software have been used extensively in qualitative studies [53]. We first imported the transformed and proofread text data into the Nvivo software, which we manually coded for aggregation, and compiled 32 valid codes for further analysis. The Nvivo Coding function was mainly used in the first step of the study. Finally, four researchers discussed and categorized their coding results, and finally, the results of the first phase of open coding are shown in Table 1.

The researchers independently abstracted and conceptualized the results on the basis of the first coding stage in the second axial coding process. Figure 4 shows an example of the Nvivo coding. Finally, when all researchers had aggregated the data, the researchers continued the discussion to produce a second axial coding result (see Table 2). In the last selective coding, the researchers individually performed the final coding, and again, indicated no disagreements with the results. Figure 5 presents the final selective coding. In this process, we used the Nvivo Note and Mindmanager software Create Table functions.

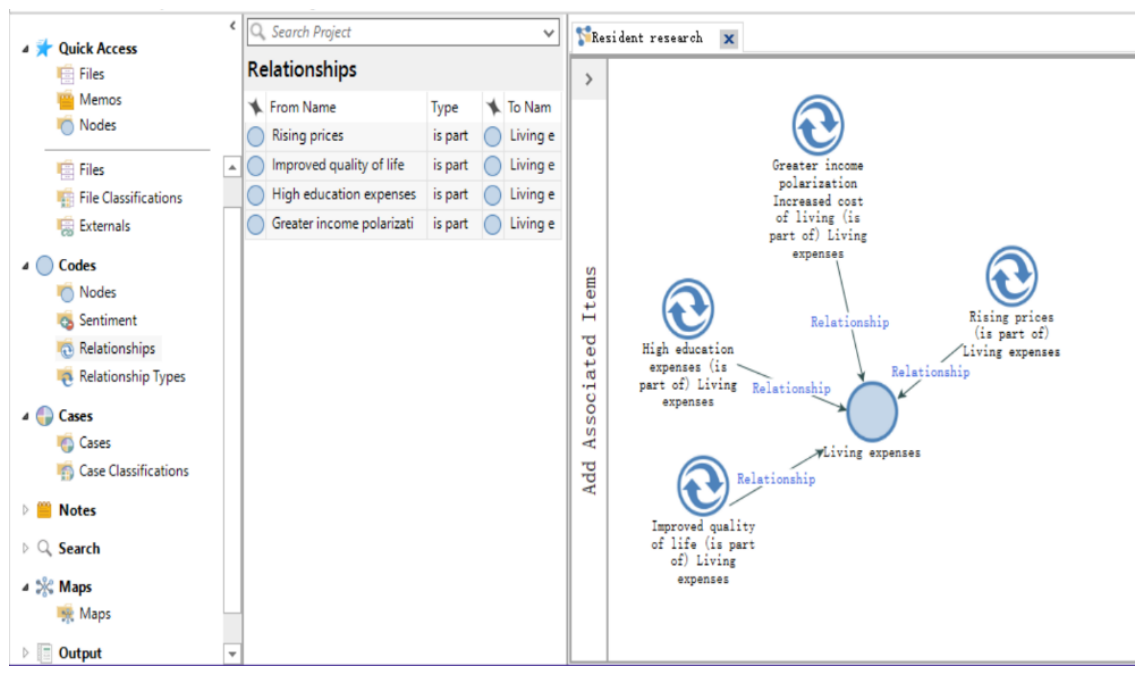

Figure 4. An example of Nvivo 12 plus analysis.

\subsubsection{Open Coding}

Open coding is a process in which the researcher decomposes, examines, compares, and conceptualizes the collected materials to identify phenomena, define concepts, and discover categories [54]. In this study, the in-depth interviews were openly coded. In this phase of the initial coding process, the numbers in the code were arranged sequentially according to the order and marked with OC (open coding) in front of the numbers (Table 1). 
Table 1. Open coding example.

\begin{tabular}{|c|c|c|c|}
\hline Code & Categories & Concepts & Interviews \\
\hline OC-1 & $\begin{array}{c}\text { Living } \\
\text { expenses }\end{array}$ & $\begin{array}{l}\text { Rising prices } \\
\text { High education expenses } \\
\text { Greater income polarization } \\
\text { Increased cost of living } \\
\text { Improved quality of life }\end{array}$ & $\begin{array}{l}\text { "Life is stressful, now in addition to living expenses, children's } \\
\text { education is the big problem, children in college, the monthly living } \\
\text { expenses will be thousands of dollars, not to mention other ... "(P01) } \\
\text { "... our village's economic income has also increased, not only family } \\
\text { equipment has improved, many people deposit, the county has a house. } \\
\text { Many foreigners have also settled here... " (P01) } \\
\text { "In recent years, many people in the village have begun to transfer their } \\
\text { own house and their own store to foreigners to operate, at ease when the } \\
\text { "landlord", business model has become more and more diverse, the level } \\
\text { also came out ... " (P01) } \\
\text { "... their own ancestral house cannot just renovate, although the scenic } \\
\text { area will give a small amount of maintenance fees, some people cannot } \\
\text { afford to buy a house in the city, the old house is dark and damp, ... } \\
\text { forced or have to spend money to buy a house in the county to pay the } \\
\text { mortgage, this kind of situation is relatively helpless." (P01) }\end{array}$ \\
\hline
\end{tabular}

\subsubsection{Axial Coding}

Axial coding takes open codes and compares them continuously, merges and clusters them to make them more directional and theoretical, and develops and establishes various relationships between concepts [52]. In this phase of the initial coding process, the numbers in the code were arranged sequentially according to the order and marked with AC (axial coding) in front of the numbers, as shown in Table 2.

Table 2. Axial coding example.

\begin{tabular}{|c|c|c|c|}
\hline Code & Categories & Concepts & Interviews \\
\hline $\mathrm{AC}-1$ & $\begin{array}{l}\text { Economic } \\
\text { Impact } \\
\text { (Positive) } \\
\text { Economic } \\
\text { impact } \\
\text { (negative) }\end{array}$ & $\begin{array}{c}\text { Land transfer fee } \\
\text { Housing rent Employment } \\
\text { status } \\
\text { Wage income } \\
\text { Daily living expenses } \\
\text { Education } \\
\text { expenses }\end{array}$ & $\begin{array}{l}\text { "In recent years, many people in the village have begun to transfer their own } \\
\text { house and their store to foreigners to operate, at ease when the "landlord", } \\
\text { the business model has become more and more diverse, the level also came } \\
\text { out" (P01) } \\
\text { "After the land transfer, most of it is to buy, and prices are rising fiercely, } \\
\text { vegetables, rice, are more expensive than before; money is not enough ..." } \\
\text { "The pressure of life, now in addition to living expenses, children's education } \\
\text { is the big head, children studying University, the monthly living expenses } \\
\text { will be several thousand dollars, not to mention other" (P01) }\end{array}$ \\
\hline
\end{tabular}

\subsubsection{Selective Coding}

Selective coding is the final coding that the researcher processes to refine the data, building on the first two steps to develop a clearer understanding of the categories [52]. The theory is constructed by comparing the core categories with other categories progressively deeper, making them more specific and refined, and integrating them with models. The positive and negative perceptions of the four core categories can lead to significant differences in attitudes and behaviors that affect tourism development in destinations, and the resulting framework of resident perceptions is shown in the Figure 5 below. 


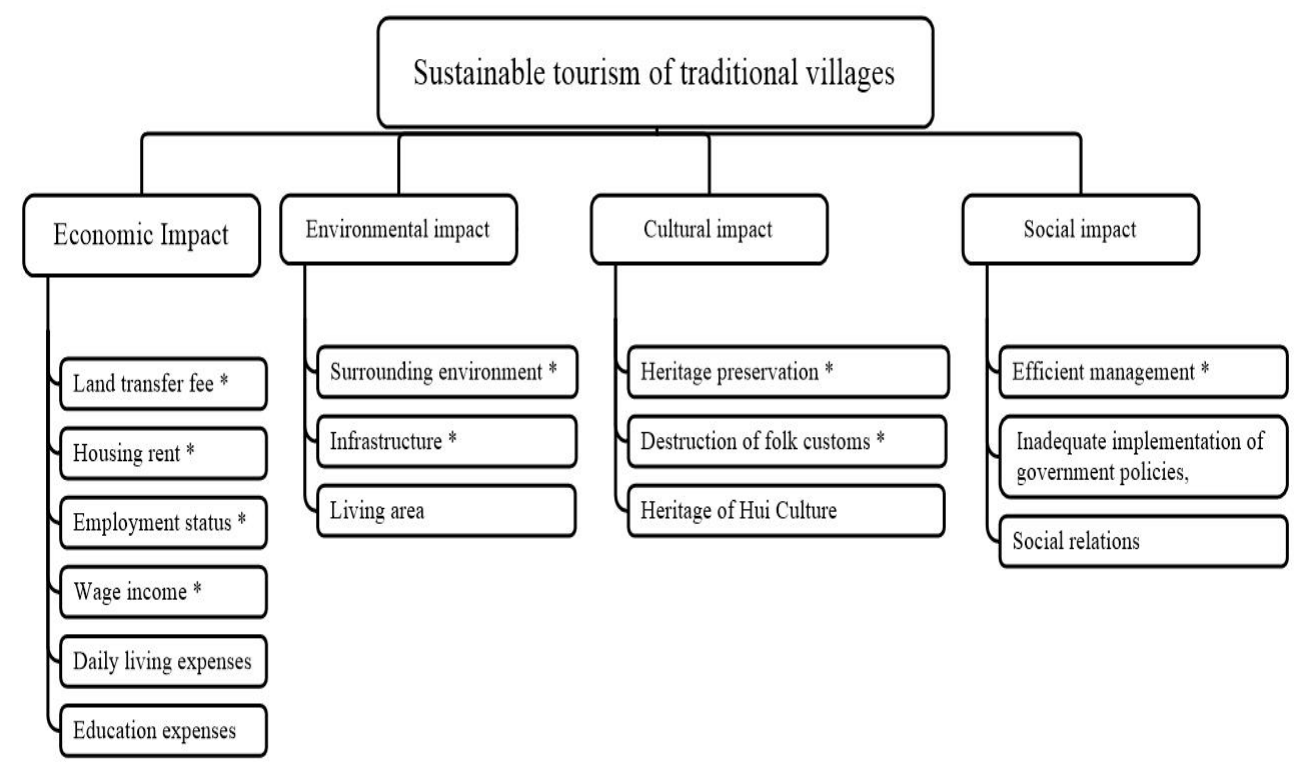

Figure 5. Theoretical framework (* means positive impact).

\section{Findings and Discussion}

\subsection{Economic Impact-Analysis of Resident Perceptions and Attitudes}

Community residents are the most central stakeholders in Hongcun [36], and the degree of benefits to residents directly affects the differences in residents' perceptions of economic impacts. At the early tourism development stage, Hongcun residents held positive perceptions of land transfer and land rents and dividends from land expropriation. Especially at the early stage of Hongcun's development, the local government actively organized residents to participate in tourism, and a large number of Hongcun residents returned to their hometown to start their businesses. From the initial selling of local specialties such as tea and dried bamboo shoots to the opening of restaurants and hotels, the real economic benefits motivated the community residents to participate in tourism-related activities continuously, and the residents were very optimistic about the comprehensive economic benefits brought by tourism, which was consistent with the results of previous studies [36].

"The old house that I could not afford to build before became a treasure, in order to develop tourism, the road was built in all directions. In the beginning, when the tourists came to the village, we locals sold some specialties, tea, bamboo shoots and so on, and then more and more tourists began to open hotels, the old people do not understand, young people came back one after another to start a business, hotels, restaurants, specialty stores batch after batch." $\mathrm{P} 02$

"Of course there is an influence, Hongcun was originally an ordinary village. It became the intangible cultural heritage protection unit, only after becoming more attention from the outside world. Now, tourism is the pillar industry of Hongcun. In recent years, Hongcun has a specialty bazaar, which is estimated to have a high attendance rate of 90\%." P06

"Tourism will promote more employment and bring some business opportunities, which is definitely good for the local people." P09

However, with the involvement of interest groups such as tourism management companies and the limitations of the community's tourism knowledge, conflicts over the distribution of benefits continue to occur. Residents are dissatisfied with the stable distribution of income and believe that tourism dividends are too small. In particular, along with the influx of tourists, residents believe that tourism development has not improved residents' quality of life but rather a calm living environment destroyed by tourism. Tourists 
occupy the productive living space of the original residents, environmental noise pollution continues to deteriorate, prices continue to rise, and residents' negative perceptions of tourism development increase significantly. This finding is consistent with the results of previous studies [55].

"Life is stressful, now in addition to living expenses, children's education is a big problem, children in college, the monthly living expenses cost several thousand, not to mention the other..." P01

"After the land transfer, most of them are bought, prices are rising fiercely, vegetables and rice are more expensive than before; money is not enough ... " P12

This study found that residents are most sensitive to the economic aspects of perceptions, and the distribution of economic benefits has the most significant degree of influence on community residents' attitudes and tourism perceptions, and obtaining economic benefits is the primary demand for community tourism, which is consistent with the results of existing studies [21]. Analyzing the reasons, it is easy to find that the fundamental driver for residents to support and participate in tourism is economic benefits, and in Hongcun, as an underdeveloped area, community residents hope that the development of tourism will bring them out of poverty and into wealth, thus paying extra attention to economic benefits. Furthermore, tourism development improves the overall economic environment and personal economic conditions, which will enhance the residents' support and tolerance for tourism development and construction. In particular, tourism practitioners who directly receive the distribution of economic benefits from tourism development in Hongcun are more likely to recognize the positive impact of tourism development than non-tourism practitioners, and the difference in the level of economic benefits from tourism can influence the community residents' perception of the impact of tourism to a greater extent. Therefore, in the interactive process of resource allocation and benefit balancing, the distribution of tourism benefits should actively consider the interests of the general community residents. In particular, non-tourism practitioners who have borne the cost of tourism development should also be given a certain proportion of benefits compensation to achieve "cost-sharing and benefit-sharing" under the dynamic balance of interests principle.

\subsection{Environmental Impact-Analysis of Resident Perceptions and Attitudes}

The environmental impact of tourism development is two-sided, and this finding reaffirms previous research findings [33,37]. In the overall analysis, Hongcun residents generally support local tourism development, but their attitudes and behaviors change over time as tourism development progresses. Nevertheless, Hongcun residents have a higher perception of the environmental improvements such as public facilities, street appearance, and infrastructure support brought by tourism development. They think that tourism development has improved the quality of life of community residents and made a greater contribution to the construction of beautiful villages. In addition, residents agree that tourism development has enhanced the awareness of environmental protection in Hongcun and improved the quality of community health, and from this perspective, community residents have a positive attitude toward the positive environmental impact of tourism.

"The development of tourism has made the overall reception environment of the village better. The parking lot and road planning are very impressive". P01

"The development of tourism in Hongcun has a great impact on the environment, not only does it have wide and flat roads, but also inns, hotels, stores and handicraft workshops, all of which are reasonably laid out. P03

As a unique humanistic tourism resource, the traditional village preserves precious sites of farming civilization. With the deepening of tourism development in Hongcun, the cultural knowledge level of the community residents has been improved, and the residents have a more comprehensive and objective understanding of tourism development. 
However, the influence of perceived economic benefits will not ultimately limit their perceptions and attitudes towards the environmental impacts caused by tourism. On the contrary, with the influx of a large number of tourists, the production and living space of local residents are squeezed, garbage is piled up, tourism development brings about the destruction of the original environment, and the negative perception of tourism environmental impact affects the residents' attitudes in support of sustainable tourism development.

"As there are too many tourists, there is more garbage and more sewage from restaurants, which is more or less damaging to the environment". P01

"There are many sketchers who come to the village, so the paint is a big source of water pollution. Although the village has many especially prepared buckets, and people will pull them out every day for special treatment, but there are always people who are not conscious and dump the wastewater from washing paints, which is very damaging to Hongcun". P11

Being the community members, local residents are the long-term feelers of environmental change and should be participants in environmental management. In the process of developing tourism, it is essential to benefit the residents as much as possible. As a stakeholder group, the stronger the positive or negative perception of the environmental impact of tourism, the more prominent their tendency to support or oppose tourism development. As the "living space" of villagers and the "visiting space" of tourists are integrated into Hongcun, the living area of residents is crowded by tourists. The overly commercialized atmosphere makes tourists lose the authenticity of the Hongcun experience and harms the interests of residents and communities, which will undoubtedly make the protection of ancient villages dependent on the participation of community residents in environmental management [36].

\subsection{Social and Cultural Impact-Analysis of Resident Perceptions and Attitudes}

Sustainable tourism development brings the most complex and challenging changes to local society and culture, and its development often creates a backlash between sustainability, which further confirms the view of [21]. During the interviews, the study found that residents believe that tourism development plays a positive role in increasing local visibility, conservation of heritage, emblematic cultural heritage, and improving the residents' pride. As witnesses of the social and cultural changes in ancient villages and inheritors of traditional culture, community residents' positive attitudes toward social and cultural preservation and the inheritance will determine the quality and direction of traditional social and cultural development in ancient villages. On the other hand, from the analysis of the interviews, the residents believe that the entry of foreign populations and commercial capital have led to some bad habits, such as gambling, alcoholism, and other adverse effects that are constantly impacting the traditional moral concepts of the past, and the residents' negative perceptions of the impact of tourism socio-culture are relatively strong.

"The local residents are more commonplace, living in the village every day, the heritage, old things should not be talking about protection, I think it should be considered the strongest group of destruction. Because they do not know why tourists come and how valuable the ancient architecture is. Usually, they decorate some old buildings with modern architectural styles for convenience and short term benefits, making them tasteless". P07

"Constructive destruction of the original cultural relics in Hongcun for commercial purposes, that is, in the name of tourism, the ancient architectural heritage of the village is arbitrarily altered, the old is demolished, and the new is built, and the walls are broken to open stores. For example, in the absence of proper planning, the ancient dwelling houses have been converted into restaurants, bed and breakfasts, and other tourist facilities to increase income. The overly commercial atmosphere not only destroys the original tranquil and simple ancient village scenery of Hongcun but also has a great negative 
impact on the protection of the ancient village heritage, to some extent leading to the loss of the historical style and making tourists lose the authenticity of the tourism experience in Hongcun." P12

It is a place where local residents live and produce, and their cultural and spiritual home. They are both the owners of the destination and part of the tourist attraction, and are an essential provider of human resources [37]. Therefore, sustainable tourism development is an essential motivation for cultural change, and the cultural development of tourist communities is influenced and permeated by the foreign culture carried by a large number of tourists, on the one hand; on the other hand, the production and lifestyle of traditional ancient villages are, in turn, favored by foreign tourists. According to [56], it was found that the degree of cultural exchange is limited by the interaction between community residents and tourists, which in turn is influenced by the communication skills and literacy level of community residents.

From an overall perspective, although the residents recognize that there are social and cultural similarities and differences, on the one hand, respondents believe that advanced foreign culture and knowledge opens the door to the world for the residents of traditional villages and expands the awareness of the community, while tourism development has brought business opportunities and vitality to the traditional villages. On the other hand, with the increasing popularity of Hongcun tourism, some small business owners and managers engaged in tourism-related businesses, as well as foreign residents, have immigrated to Hongcun, and this degree of social integration between foreign immigrants and aborigines has brought impacts and challenges to traditional social and cultural changes and sustainable tourism development. Revitalizing the local culture and keeping it alive is inseparable from the efficient management of the government and the active participation of the community residents, who should become the last and most stubborn line of defense to protect cultural authenticity. Therefore, it is essential to pay attention to the positive social and cultural interaction and communication between tourists and community residents, as well as between the original residents and new immigrants, to reduce conflicts and contradictions through social and cultural interaction and communication, and to continuously promote the deep psychological and cultural integration between community residents, tourists and immigrants.

\section{Conclusions and Limitations}

This study adopted a qualitative research method based on stakeholder theory with semi-structured in-depth interviews to explore the perceptions and attitude differences of traditional village residents with different stakeholders on the sustainable development of tourism in Hongcun. The study found that Hongcun residents' perceptions and attitudes toward the impact of tourism showed dynamic changes. Over time, while residents held positive perceptions and optimistic attitudes toward the economic, environmental, social, and cultural impacts of sustainable tourism development, the degree of negative perceptions toward the economic, environmental, and socio-cultural impacts also increased significantly. This is mainly due to the contradiction in the distribution of benefits, which leads to a change in the degree of benefit to the residents and directly affects their perceptions. In particular, the phenomenon of two-way mobility between urban and rural areas of ancient towns has led to a change in the relationship between host and client, bringing new challenges to the development of local tourism. As a whole, the sustainable economic, environmental and social-cultural development of Hongcun can only be achieved with the participation and support of all community residents, whether they are new immigrants or former residents.

Additionally, this study provides some theoretical implications for future related studies. The four themes under which this study categorizes the factors affecting residents' perceptions and differences in attitudes include economic, environmental, social and cultural influences and several sub-themes. Thus, it enriches the stakeholder theory in the study of traditional villages. From the overall analysis, Hongcun residents generally 
support the development of local tourism. However, as tourism development continues, residents' attitudes and behaviors are changing. In particular, during the COVID-19 pandemic, the "pause button" was pressed on tourism development in Hongcun. As a result, the direct and indirect economic benefits that community residents receive from tourism development are significantly reduced, prompting residents to evaluate and understand the impacts of sustainable tourism development in a more comprehensive, objective, and rational manner. Previous studies focused on quantitative research, and there is a lack of qualitative research to explore the psychological changes of residents in the current era [15]. This study explores the perceptions and attitudes of different stakeholders in sustainable tourism development based on economic, environmental, and socio-cultural perspectives. Thus, this finding fills a gap in previous research on stakeholder theory in traditional villages.

Finally, the profound development of Hongcun tourism should be promoted. As the leading force for realizing the sustainable development of Hongcun tourism, Chinese government departments should strengthen government intervention in the development process of Hongcun and ensure the orderly development of Hongcun by legal means such as systems and rules; at the same time, they should regularly train local residents to improve their awareness of sustainable tourism development and professional skill level and create an environment atmosphere of autonomy and self-care for Hongcun community residents. At the level of tourism enterprises, the tourism development company should give advantages to the leading local enterprises, deeply excavate the local characteristics of Hui culture, and make the brand of Hongcun bigger and stronger. In particular, they should focus on developing different types of thematic tourism products such as scientific research tour, study tour, rural tour, and actively broaden the market of Hongcun tourism sources. On the other hand, they should integrate local resources, cooperate with Huangshan Mountain and the surrounding scenic spots, improve joint marketing, continuously improve the visibility and brand benefits of Hongcun, continuously help local residents gain economic benefits from tourism development, and properly handle the relationship between commercial development and heritage protection.

This study has limitations. First, this study is exploratory and focuses on a single case. Generalization of implications should be cautious. However, this study aims to develop a theoretical framework for future related and similar traditional village studies. Thus, future studies can be further studied by respondents from different backgrounds and different traditional villages. Second, because a tourist place is a continuous dynamic process, the perceived attitudes of community residents may change with different stages of tourism development, the amount of capital investment by tourism enterprises, and changes in local policies. Therefore, future studies need to conduct continuous follow-up surveys of the case sites and use a combination of qualitative and quantitative research methods to further understand the influence of residents on the future long-term sustainable development support of Hongcun through the analysis of dynamic difference factors.

Author Contributions: Conceptualization, H.S.; methodology, H.S.; software, C.Z.; validation, H.S., C.Z. and L.H.N.F.; formal analysis, H.S.; investigation, H.S.; resources, H.S.; data curation, C.Z.; writing-original draft preparation, C.Z.; writing-review and editing, L.H.N.F.; visualization, C.Z.; supervision, L.H.N.F.; project administration, L.H.N.F. All authors have read and agreed to the published version of the manuscript.

Funding: This research received no external funding.

Institutional Review Board Statement: Ethical review and approval were waived for this study, due to the collected data were based on interviews with traditional village residents whose answers remain anonymous.

Informed Consent Statement: Informed consent was obtained from all subjects involved in the study.

Data Availability Statement: Not applicable.

Conflicts of Interest: The authors declare no conflict of interest. 


\section{Appendix A}

Table A1. A background of respondents.

\begin{tabular}{cccccc}
\hline Informant No. & Permanent Address & Gender & Age & Education & Job \\
\hline P01 & Lu an, Anhui & Female & 35 & Junior College & Guided Tours \\
P02 & Yixian County, Anhui & Female & 36 & Junior College & B\&B owner \\
P03 & Yixian County, Anhui & Male & 40 & Master & Hotel owner \\
P04 & Hefei, Anhui & Female & 68 & Bachelor & Retired university teacher \\
P05 & Zhuhai, Guangdong & Female & 31 & PhD & scholar \\
P06 & Huangshan, Anhui & Male & 39 & PhD & University teacher \\
P07 & Yixian County, Anhui & Male & 43 & Bachelor & Resident \\
P08 & Hefei, Anhui & Male & 31 & Master & scholar \\
P09 & Huangshan, Anhui & Male & 35 & Master & Government Staff \\
P10 & Yixian County, Anhui & Female & 55 & High School & Village official \\
P11 & Nanjing, Jiangsu & Male & 40 & Bachelor & Freelance Painter \\
P12 & Hefei, Anhui & Male & 45 & PhD & University teacher \\
\hline
\end{tabular}

\section{References}

1. Bohua, L.; Sha, Y.; Peilin, L.; Yindi, D.O.U. Spatial Distribution of Traditional Villages and Influence Factors in Hunan Province. J. Landsc. Res. 2016, 8, 63-67.

2. Gao, J.; Wu, B. Revitalizing Traditional Villages through Rural Tourism: A Case Study of Yuanjia Village, Shaanxi Province, China. Tour. Manag. 2017, 63, 223-233. [CrossRef]

3. Zhuang, X.; Yao, Y.; Li, J.J. Sociocultural Impacts of Tourism on Residents of World Cultural Heritage Sites in China. Sustainability 2019, 11, 840. [CrossRef]

4. Graburn, N.; Jin, L. Tourism and Museums in China. Asian J. Tour. Res. 2017, 2, 1-35. [CrossRef]

5. Liangwen, Z.H.U. Reflection on Traditional Villages. J. Landsc. Res. 2017, 9, 35-40.

6. Alrwajfah, M.M.; Almeida-García, F.; Cortés-Macías, R. Residents' Perceptions and Satisfaction toward Tourism Development: A Case Study of Petra Region, Jordan. Sustainability 2019, 11, 1907. [CrossRef]

7. Khazaei, A.; Elliot, S.; Joppe, M. An Application of Stakeholder Theory to Advance Community Participation in Tourism Planning: The Case for Engaging Immigrants as Fringe Stakeholders. J. Sustain. Tour. 2015, 23, 1049-1062. [CrossRef]

8. Pjerotić, L.; Ra \djenović, M.; Tripković-Marković, A. Stakeholder Colaboration in Tourism Destination Planning-The Case of Montenegro. ECONOMICS-Innov. Econ. Res. 2016, 4, 119-136. [CrossRef]

9. Buultjens, J.; White, N.; Neale, K. Collaborative Destination Management Planning: A Case Study of Byron Bay, Australia. J. Travel Tour. Res. 2012, 12, 18.

10. Pjerotić, L.; Radjenović, M.; Marković, A.T. Stakeholder Cooperation in Montenegrin Tourism Destinations-Current State and Constraints. Facta Univ. Ser. Econ. Organ. 2016, 13, 87-100.

11. Boom, S.; Weijschede, J.; Melissen, F.; Koens, K.; Mayer, I. Identifying Stakeholder Perspectives and Worldviews on Sustainable Urban Tourism Development Using a Q-Sort Methodology. Curr. Issues Tour. 2021, 24, 520-535. [CrossRef]

12. Lewis, A. Rationalising a Tourism Curriculum for Sustainable Tourism Development in Small Island States: A Stakeholder Perspective. Crit. Issues Tour. Educ. 2004, 4, 9-15. [CrossRef]

13. Theodoulidis, B.; Diaz, D.; Crotto, F.; Rancati, E. Exploring Corporate Social Responsibility and Financial Performance through Stakeholder Theory in the Tourism Industries. Tour. Manag. 2017, 62, 173-188. [CrossRef]

14. Freeman, R. Strategic Management: A Stakeholder Approach; Cambridge University Press: Boston, PA, USA, 1984.

15. Byrd, E.T. Stakeholders in Sustainable Tourism Development and Their Roles: Applying Stakeholder Theory to Sustainable Tourism Development. Tour. Rev. 2007, 62, 6-13. [CrossRef]

16. Gursoy, D.; Jurowski, C.; Uysal, M. Resident Attitudes: A Structural Modeling Approach. Ann. Tour. Res. 2002, 29 , 79-105. [CrossRef]

17. Easterling, D.S. The Residents' Perspective in Tourism Research: A Review and Synthesis. J. Travel Tour. Mark. 2005, 17, 45-62. [CrossRef]

18. Nicholas, L.N.; Thapa, B.; Ko, Y.J. Residents'perspectives of a World Heritage Site: The Pitons Management Area, St. Lucia. Ann. Tour. Res. 2009, 36, 390-412. [CrossRef]

19. Rasoolimanesh, S.M.; Roldán, J.L.; Jaafar, M.; Ramayah, T. Factors Influencing Residents' Perceptions toward Tourism Development: Differences across Rural and Urban World Heritage Sites. J. Travel Res. 2017, 56, 760-775. [CrossRef]

20. Nunkoo, R.; Ramkissoon, H. Stakeholders' Views of Enclave Tourism: A Grounded Theory Approach. J. Hosp. Tour. Res. 2016, 40, 557-558. [CrossRef]

21. Almeida-García, F.; Pelaez-Fernandez, M.A.; Balbuena-Vazquez, A.; Cortés-Macias, R. Residents' Perceptions of Tourism Development in Benalmádena (Spain). Tour. Manag. 2016, 54, 259-274. [CrossRef] 
22. Látková, P.; Vogt, C.A. Residents' Attitudes toward Existing and Future Tourism Development in Rural Communities. J. Travel Res. 2012, 51, 50-67. [CrossRef]

23. Ritchie, J.B.; Crouch, G.I. The Competitive Destination: A Sustainable Tourism Perspective; CABI: Oxford, UK, 2003.

24. Rivera, M.; Croes, R.; Lee, S.H. Tourism Development and Happiness: A Residents' Perspective. J. Destin. Mark. Manag. 2016, 5, 5-15. [CrossRef]

25. Munasinghe, M. Sustainable Development in Practice; Cambridge: New York, NY, USA, 2009.

26. Butler, R.W. Sustainable Tourism: A State-of-the-Art Review. Tour. Geogr. 1999, 1, 7-25. [CrossRef]

27. Li, M. Cultural Subjectivity in Intercultural Communication. Int. J. Arts Sci. 2010, 3, 272-285.

28. Ahmed, Z.U.; Krohn, F.B. Understanding the Unique Consumer Behavior of Japanese Tourists. J. Travel Tour. Mark. 1993, 1, 73-86. [CrossRef]

29. Backman, K.F.; Backman, S.J. An Examination of the Impacts of Tourism in a Gateway Community. Dev. Qual. Life Stud. 1997, 1, 6.

30. Sharpley, R. Host Perceptions of Tourism: A Review of the Research. Tour. Manag. 2014, 42, 37-49. [CrossRef]

31. Hateftabar, F.; Chapuis, J.M. How Resident Perception of Economic Crisis Influences Their Perception of Tourism. J. Hosp. Tour. Manag. 2020, 43, 157-168. [CrossRef]

32. Long, P.T.; Perdue, R.R.; Allen, L. Rural Resident Tourism Perceptions and Attitudes by Community Level of Tourism. J. Travel Res. 1990, 28, 3-9. [CrossRef]

33. Lee, T.H.; Jan, F.-H. Can Community-Based Tourism Contribute to Sustainable Development? Evidence from Residents' Perceptions of the Sustainability. Tour. Manag. 2019, 70, 368-380. [CrossRef]

34. Mbaiwa, J.E. The Socio-Cultural Impacts of Tourism Development in the Okavango Delta, Botswana. J. Tour. Cult. Chang. 2005, 2, 163-185. [CrossRef]

35. Wang, J.; Xie, L.; Zhang, S. Residents' Perceptions and Participation in Dark Tourism on Natural Disaster Site-A Case Study of Jina Qiang Stockaded Village, China. Tour. Trib. 2020, 2020, 1-18.

36. Guo, A.; Wang, S.; Li, H.; Guo, Y. Influence Mechanism of Residents' Perception of Tourism Impacts on Supporting Tourism Development: Intermediary Role of Community Satisfaction and Community Identity. Tour. Trib. 2020, 35, 96-108.

37. Rasoolimanesh, S.M.; Ringle, C.M.; Jaafar, M.; Ramayah, T. Urban vs. Rural Destinations: Residents' Perceptions, Community Participation and Support for Tourism Development. Tour. Manag. 2017, 60, 147-158. [CrossRef]

38. Higham, J. Commentary-Sport as an Avenue of Tourism Development: An Analysis of the Positive and Negative Impacts of Sport Tourism. Curr. Issues Tour. 1999, 2, 82-90. [CrossRef]

39. Boukas, N.; Ziakas, V. Tourism Policy and Residents' Well-Being in Cyprus: Opportunities and Challenges for Developing an inside-out Destination Management Approach. J. Destin. Mark. Manag. 2016, 5, 44-54. [CrossRef]

40. Ukaegbu, M.O.; Carr, N.; Okpoko, P.U. Local People's Perceptions of the Potential Implications of Cultural Revitalisation through Tourism in Benin, Nigeria. J. Tour. Cult. Chang. 2020, 18, 455-469. [CrossRef]

41. Rasoolimanesh, S.M.; Taheri, B.; Gannon, M.; Vafaei-Zadeh, A.; Hanifah, H. Does Living in the Vicinity of Heritage Tourism Sites Influence Residents' Perceptions and Attitudes? J. Sustain. Tour. 2019, 27, 1295-1317. [CrossRef]

42. Teye, V.; Sirakaya, E.; Sönmez, S.F. Residents' Attitudes toward Tourism Development. Ann. Tour. Res. 2002, 29, 668-688. [CrossRef]

43. Yu, C.-P.; Charles Chancellor, H.; Tian Cole, S. Examining the Effects of Tourism Impacts on Resident Quality of Life: Evidence from Rural Midwestern Communities in USA. Int. J. Tour. Sci. 2011, 11, 161-186. [CrossRef]

44. Moghavvemi, S.; Woosnam, K.M.; Paramanathan, T.; Musa, G.; Hamzah, A. The Effect of Residents' Personality, Emotional Solidarity, and Community Commitment on Support for Tourism Development. Tour. Manag. 2017, 63, 242-254. [CrossRef]

45. Miles, M.B.; Huberman, A.M. Qualitative Data Analysis: An Expanded Sourcebook; Sage: Thousand Oaks, CA, USA, 1994.

46. Dworkin, S.L. Sample Size Policy for Qualitative Studies Using In-Depth Interviews; Springer: Berlin/Heidelberg, Germany, 2012.

47. Yin, R.K. Applications of Case Study Research; Sage: Thousand Oaks, CA, USA, 2011.

48. Boyce, C.; Neale, P. Conducting In-Depth Interviews: A Guide for Designing and Conducting in-Depth Interviews for Evaluation Input; Pathfinder International: Watertown, MA, USA, 2006.

49. Bryman, A. Sampling in Qualitative Research. Soc. Res. Methods 2012, 4, 415-429.

50. Momeni, K.; Janati, A.; Imani, A.; Khodayari-Zarnaq, R. Barriers to the Development of Medical Tourism in East Azerbaijan Province, Iran: A Qualitative Study. Tour. Manag. 2018, 69, 307-316. [CrossRef]

51. Samadbeik, M.; Asadi, H.; Mohseni, M.; Takbiri, A.; Moosavi, A.; Garavand, A. Designing a Medical Tourism Website: A Qualitative Study. Iran. J. Public Health 2017, 46, 249.

52. Corbin, J.; Strauss, A. Basics of Qualitative Research: Techniques and Procedures for Developing Grounded Theory; Sage Publications: Thousand Oaks, CA, USA, 2014.

53. Bazeley, P.; Jackson, K. Perspectives: Qualitative Computing and NVivo; Sage: London, UK, 2013; pp. 1-46.

54. Glaser, B.G.; Strauss, A.L. The Discovery of Grounded Theory: Strategies for Qualitative Research; Routledge: Oxford, UK, 2017.

55. Lee, C.-K.; Kim, S.-S.; Kang, S. Perceptions of Casino Impacts-a Korean Longitudinal Study. Tour. Manag. 2003, $24,45-55$. [CrossRef]

56. Tosun, C. Host Perceptions of Impacts: A Comparative Tourism Study. Ann. Tour. Res. 2002, 29, 231-253. [CrossRef] 